\title{
Research on the Cultivation Mode of Innovative Talents during the College Physical Education
}

\author{
Jing-lun Yang ${ }^{1, a}$, Lan Chen ${ }^{2, b}$ \\ ${ }^{1}$ Sports education center,Zhuhai College of Jilin University,Zhuhai 519041,China \\ ${ }^{2}$ Laboratory and assets management office,Zhuhai College of Jilin University, Zhuhai 519041,China \\ ayangjinglun1983@163.com, ${ }^{b}$ chenlan19841009@163.com
}

Keywords: higher education, college, physical education, innovative talent cultivation

\begin{abstract}
As the higher education becomes more and more popular in China, it is necessary to comprehensively implement the effective innovation education. It is considered as one of the important missions for the reform of higher education. In this paper, the existing problems and constraints on the development of innovative talents are analyzed including the outdated concept, old-fashioned education pattern, lack of innovation ability for the physical education teachers and short of teaching resources. During the college physical education, it is essential to change the outdated ideas, deepen the reform of physical education approaches, strengthen the construction of the physical education teachers and manage the construction and maintenance of teaching hardware resources. In this way, the practical and effective innovation education shall be lanuched in the college so as to cultivate more innovative talents.
\end{abstract}

\section{Introduction}

In China, the higher education is developing in a quicker way. According to our reform of higher education, it is necessary for the colleges to comprehensively carry out the innovation education and improve the student's creative spirit and ability of practice. Thus the students are capable to adapt to the complex employment environment and keep a positive attitude towards the severe job challenge ${ }^{[1]}$. The innovative talents are full of youthful spirit and creative spirit in the society. At the same time, the national development is subject to the cultivation of innovative talents.As an important component of higher education, the physical education plays a crucial role in the progress of the student's teamwork, capacity of analytical thinking and innovation capability ${ }^{[2]}$. Based on the characteristics of physical education in the college, the active development of innovative talents are beneficial to completely promote the well-rounded education and improve their creative spirit and practical ability.

\section{Discuss the constraints on the development of innovative talents in the college physical education.}

2.1 Outdated concept In the strategic and global sense, the innovative teaching patterns can further promote the student's innovation spirit and ability of practice, improve the teaching quality of the college physical education, achieve the sustainable development of talent cultivation, enhance the social service quality for the higher institutions, and promote the regional economic development ${ }^{[3]}$. On account of the concept of conventional education, there is the bias of our ideological understanding on the cultivation of innovative talents in the society. It is believed that the physical education is a process of doing the physical exercises while the cultivation of innovative talents depends on the development of other disciplines. As a consequence, the government, colleges or even physical education teachers have not paid enough attentions on the cultivation of innovative talents during the college physical education. This kind of narrow ideas is partially reflected as follows: the government does not offer the comprehensive support on the cultivation of innovative talents; the colleges insist on the existing outdated education system rather than the innovative teaching modes; 
the development of innovative talents is restricted as the teachers have not made the new researches on the related thoery and practices during the physical education ${ }^{[4]}$.

2.2 Education mode With regard to the other disciplines, the innovative education mode is much sophisticated. In our country, the college has just started and explored the cultivation of innovation talents. The existing problems are majorly illustrated as follows: on the one hand, the majority of the colleges still adopt the coventional teaching modes, for instance the colleges will adopted the teaching of academic programs, guidance of the teachers and static assessment. During the teaching process, the academic programs are limited; the curriculum system is based on the small area of knowledge and all-inclusive aspects; the theoretical knowledge is dominated during the teaching process. Thus it is much difficulut to set up the innovative teaching mode and improve the student's creative capability; on the other hand, the interactive teaching modes are not fully executed. It seems that the student's conscious activities like the desire of independent learning and innovation researches are ignored. In terms of the conventional teaching mode, the knowledge instruction is concerned while the ability of practice is overlooked. Under such circumstances, the student's innovation consciousness is greatly restricted in hindering the development of their innovative capacity $^{[5]}$.

2.3 Construction of physical education teachers With the development of innovative education, it is required to cultivate the student's innovation ability including the favorable ideological and moral quality, psychological quality, insight, judgement ability and other professional quality. It has placed the higher requirements on the physical education teachers during the development of innovative education ${ }^{[6]}$. In general, the physical education teachers are not reasonably arranged; the comprehensive quality for the physical education teachers shall be further improved. The unreasonable distribution of the physical education teachers is majorly reflected as follows: the physical education teachers become younger and younger; the majority of the teachers have just obtained the primary and medium-grade professional titles. There are a few of teachers with the high-grade qualifications. In other words, the colleges are lack of the qualified teachers whom can take the lead of the other physical education teachers and keep the continuous development of the innovative education. From the aspect of the teacher's comprehensive ability, there are lower requirements on the employment of the physical education teachers. These teachers have the lower academic levels, lack of dedication spirit, low sense of responsbility, narrow scope of knowledge, outdated knowledge, lack of innovation spirit and experiences, content with their current situation, no attempt to make progress and difficulty in meeting the requirements of new age ${ }^{[7]}$. During the physical education, it is urgent to transform the physical education teacher's teaching concepts and improve their professional ethnics, innovation spirit, professional knowledge, knowledge structure and teaching ability. In this way, the physical education teachers are possible to meet the requirements on the cultivation of innovative talents in the new age.

2.4 Poor teaching resources and maintenance During the physical education, the important components of teaching resources include training ground, teaching facilities, gymnasium, etc. At the initial stage of building the schools, the statium and teaching facilities are constructed and invested; the existing teaching resources are required for the stable management; thus it is important to make the daily management and maintenance on the teaching resources instead of renewing the teaching resources. The existing teaching resources can not match with the requirements of the increasing students year by year. The lack of the physical teaching resources produces a great influence in the student's enthusiasm and further development of innovative education. At the same time, there are the existing problems like the lack of enough attentions from the leaders, imperfect teaching system, unrealistic reward and punishment mechanism. While the teachers, administrative staff and the students are taking advantages of these teaching resources, it is easy to arouse the problems of unreasonable usage, poor management, poor maintenance and delayed repairs. In this case, it will influence the normal use of teaching resources, bring about the wastes of the teaching resources and prevent the smooth development of innovative talents during the physical education. 


\section{Research on the development of innovative talents during the college physical education.}

3.1 Transformation of education concept The cultivation of innovative talents is of great importance to broaden the student's knowledge and improve their skills and practical ability as well as emphasis on the education of the student's ideology, thinking modes and behaviors. In other words, the convetional education management and teaching modes can not meet the social demands during the cultivation of college students. With the coming of new ages, it is urgent to transform the old-fashioned education concept on the cultivation of innovative talents, keep pace with the times, establish the proper education concept, put the innovative education concept into practice and actively push forward the cultivation of innovative talents in the college.

Firstly, the government shall achieve the thought liberation, actively push forward the education reform, intensify the policy support and encourage all levels of the society to engage into the cultivation of innovative talents in the college; next, the colleges should respond to the demands on the cultivation of innovative talents in the new age, make great attempts to the development of the innovative talents, set up the effective incentive policy and arouse the physical education teacher's enthusiasm in the college; finally, the physical education teachers shall pay enough attentions to the development of innovative talents during the teaching process, strengthen the theory research and optimize the knowledge structures on the cultivation of innovative talents. During the teaching process, it is necessary to actively carry out the reform of physical education and cultivate more talents with the strong social adaptiveness .

3.2 Deepen the reform of physical education curriculum and focus on the training of innovation ability In the new age, the concepts of "quality-oriented education", "lifelong sports" and "health first" and "innovative talents" have been proposed. It also exerts a great influence in the physical education in the college. The college mangement shall make an active response on the market requirements, keep pace with the development of times, and design some new and specific curriculum on the physical education. In particular, it needs to focus on the settings of optional courses on the cultivation of innovative talents. In this way, it is convenient for the students to independently choose the physical education curriculum, achieve the flexible learning mode and make a comprehensive development. During the teaching process, it is possible to meet the student's requirements on the personality development and improve the student's innovation ability. In terms of the reform of college education, the conventional teaching methods and assessment modes shall be changed; the physical education teachers are motivated to develop the innovative education; the students are motivated to improve the ability of practices, make more physical exercises outside the classroom and improve the innovative ability and overall quality in the different levels and aspects. The existing problems of poor practical ability, lack of personality and innovative ideas are solved.

3.3 Reinforce the construction of physical education teachers The physical education teachers are seen as the important human resources as well as the primary components of the college's core competence during the development of innovative talents. As long as the physical education teachers with the higher comprehensive quality and innovation consciousness are rationally constructed, it is likely to achieve the sustainable development on the cultivation of innovative talents. At present, it is necessary to organize a team of potentional and qualified teachers whom can make the great contributions to the cultivation of innotivate talents. On the one hand, the college management are capable to make the sustainable development policy, for instance, the calculation of tuition fees, promotion of professional titles, social benefits, personnel training, assessment mechanism, etc; on the other hand, it is necessary to insist on the "internal personnel training and external introduction", namely do well with the training of the college teachers and introduce more new teachers. From the aspect of teaching modes and scientific research, the innovative ability and practical ability for the young physical education teachers shall also be improved. At the same time, the physical education teaachers shall be prepared for the challenges, keep a right attitude towards the fast development of the today's society, meet the requirements of education reform, have a correct understanding on the update of knowledge, adapt to the new positions, improve the individual professional qualification, 
make a continuous learning, constantly improve themselves and face to the new challegents during the process of social transition and education reform.

3.4 Increase the funds and reinforce the daily maintenance and management As the material basis of physical education, it is necessary to add the teaching resources of sports facilities and fields, do well with the daily maintenance and keep the availability of the teaching hardwares so as to guarantee the smooth development of innovative talents. In the college, the management shall focus on the construction of teaching resources, add the funds from the multiple channels, strengthen the infrastructure construction, do well with the maintenance in the later stage and create the conditions. Thus the students have the opportunity to do the on-site physical exercises with a plenty of teaching facilities. During the process of raising the funds, the colleges can offer the paid field service for the community, enterprises and social institutions on the weekend, holiday and winter and summer vacation. In this way, it is possible to raise the funds from the local residents and put the raised funds into the daily maintenance. In terms of the field maintenance, it is necessary to formulate the explicit regulations on the daily management, maintenance management, rewards and punishment. What's more, the full-time asset director shall be assumed to take charge of the daily management and maintenance and guarantee the normal usage of the school field and teaching facilities.

\section{Summary}

As the market economy is constantly improved, the cultivation of innovative talents is a key part of the innovative education. In this case, it has made new demands on the quality of our physical education. In contrast to the other subject education, the physical education plays a considerable role in the higher education. During the teaching process, it is likely to improve the student's learning initiatives, independence, social communication, ability of exploration, decision-making ability, innovative ability and pursuit of excellence. With the coming of new ages, the innovative talents are required to improve these essential abilities and characters. The college management must get a clear understanding of the current situations, change the outdated ideas, deepen the reform of physical education curriculum, strengthen the construction of the physical education teachers, add the physical teaching resources and encourage the physical education teachers to make the devotion on the innovative talent cultivation. It is designed to strengthen the student's coordinated development on the knowllege, ability, quality and personality. During the teaching process, the students are encouraged to improve the ability of practice, innovation ability and ability of scientific research.

\section{References}

[1] Lu Yuanyuan, Research on the career-creating talent cultivation for our sports college, Shanghai University Of Sport, 2011.

[2] Zhu Ailing, Research on "platform + module” innovative training system of physical education in the college, Ningbo University, 2009.

[3] Caoruihua, Zhangpenghai, Discuss the current situation and systmatic development of innovative talents during the physical education, Education And Vocation,2013,03:99-101.

[4] Liu Dongju, Establish the cultivation mode of career-creating talents in the college, Journal Of Yangzhou University(Higher Education Study Edition),2007,02:67-70.

[5] Huang Zhimei, New curriculum reform on the healthy sports activities, Learning Weekly,2016,08:211.

[6] Ye Chunjuan, Explore the current situation and improvement measures for physical education teachers in the college, Education And Vocation,2015,23:61-63.

[7] Wang Junhong, Explore the current situation and strategy on the construction of physical education teachers in the college, Education And Vocation,2015,27:67-69. 